\title{
Parity-A Call for the Worldwide Condemnation and Criminalization of Infant Male Genital Mutilation [Circumcision]
}

ISSN: 2578-0379

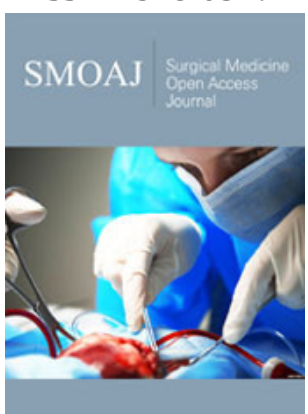

*Corresponding author: Mister SA, Independent Researcher, Nigeria

Submission: 㭗 November 20, 2020

Published: 制 December 09, 2020

Volume 4 - Issue 1

How to cite this article: Mister SA. Parity-A Call for the Worldwide Condemnation and Criminalization of Infant Male Genital Mutilation [Circumcision]. Surg Med Open Acc J. 4(1). SMOAJ.000580. 2020. DOI: 10.31031/SMOAJ.2020.04.000580

Copyright@ Mister SA, This article is distributed under the terms of the Creative Commons Attribution 4.0 International License, which permits unrestricted use and redistribution provided that the original author and source are credited.

\section{Mister SA*}

Independent Researcher, Nigeria

\section{Opinion}

Female genital mutilation has been condemned far more than male genital mutilation. There seems to be a conspiracy in the scientific community to ignore the benefits of the intact prepuce (foreskin) and to deny the horrors of male genital mutilation. Science and human rights must always trump and triumph over superstition. The prepuce is on the penis for a purpose. The foreskin/prepuce is not something to be jettisoned like the umbilical cord. When the umbilical cord is severed neither baby nor mother feel any pain. Why? Because there are no nerves in the umbilical cord. Ditto when fingernails or hair is cut. Is this the case when an infant male is mutilated/circumcised? Not at all. Male circumcision in both infant and adult males produces pain lasting from hours to days. This is because the foreskin/ prepuce is innervated. The prepuce has somatosensory nerves linked to the oral nerve of the penis and branching into the scrotum. Not to mention autonomic nerves from the pelvic plexus. The prepuce protects the glans penis and urinary meatus. The foreskin contains Meissner corpuscles and natural lubricants. The bottom line is that the prepuce/foreskin is a fully fledged and essential body part-not an appendage to be excised. Nor is it temporary or transitory like milk teeth. The prepuce has a purpose. It lowers penis temperature, increases penis girth, protects the penis from chaffing and increases comfort and pleasure during coitus. And who knows which other functions of the foreskin scientists might discover in the future?

Enough is enough! Let us put an end to this barbaric child abuse called circumcision. Countries with infant male genital mutilation rates above 95\% include Turkey, Afghanistan, Algeria, Azerbaijan, Pakistan, Eritrea, Gabon, Iran, Iraq, Jordan, Nigeria, Tunisia, Togo, Saudi Arabia, Yemen, Uzbekistan and Tajikistan. Countries with infant male genital mutilation rates below 10\% include Japan, Greece, Italy, Norway, Denmark, Argentina and Austria [1-11].

\section{References}

1. Your baby boy's circumcision: What to expect.

2. Guy AB, Justine MS, Heino FL, Meyer B, Guy TS, et al. (2013) Male circumcision decreases penile sensitivity as measured in a large cohort. Sexual Medicine 111(5): 820-827.

3. Morris BJ, Moreton S, Krieger JN (2019) Critical evaluation of arguments opposing male circumcision: A systematic review. J Evid Based Med 12(4): 263-290.

4. Circumcised vs uncircumcised: Pros and cons to consider.

5. Elizabeth AP, Justin MA (2019) Male circumcision: The clinical implications are more than skin deep. Mo Med 116(1): 35-37.

6. Michael JB, John BZ, Sean EK, Adrian M, Alex DW, et al. (2013) Recommendation by a law body to ban infant male circumcision has serious worldwide implications for pediatric practice and human rights. BMC Pediatrics 13: 136

7. Mikaela C (2011) Proposed circumcision ban struck from San Francisco ballot. 
8. Iceland law to outlaw male circumcision sparks row over religious freedom.

9. Cold CJ, Taylor JR (1999) The prepuce. British Journal of Urology 83(S1): 34-44.
10. Table 1 Percentage of circumcised males in each of the 237 countries and territories in the world.

11. Esther BH, Aaron ART, Jeffrey DK, Joya B, Catherine AH, et al. (2016) Estimation of country-specific and global prevalence of male circumcision Popul Health Metr 14: 4.

For possible submissions Click below: 